\title{
O BRINCAR NA INFÂNCIA E O PROFESSOR DE EDUCAÇÃO FÍSICA
}

Recebido em: 20/03/2013

Aceito em: 10/12/2013

\author{
Alana Simões Bezerra ${ }^{1}$ \\ Dafne Souto Macedo ${ }^{2}$ \\ Thaiza Isidro Vieira ${ }^{3}$ \\ Pierre Normando Gomes-da-Silva ${ }^{4}$ \\ Universidade Federal da Paraíba - UFPB \\ João Pessoa - PB - Brasil
}

RESUMO: O presente objetiva analisar a contribuição do brinquedo e das brincadeiras, vivenciadas na infância, para a formação inicial dos professores de Educação Física. A pesquisa foi realizada com 27 estudantes do $5^{\circ}$ período do curso de Educação Física da Universidade Federal da Paraíba, os mesmos responderam a um questionário estruturado. Os dados foram analisados a partir da técnica de análise de conteúdo. Segundo os participantes da pesquisa, a utilização do brinquedo em suas aulas facilita o processo de ensino-aprendizagem, proporciona o desenvolvimento motor adequado, faz uso nas aulas de brincadeiras populares e auxilia ao ensinar o valor de convivência. Sendo assim, consideramos importante o resgate da cultura dos brinquedos na formação dos professores de Educação Física, tendo em vista o processo de autoformação e dos saberes de experiências.

PALAVRAS CHAVE: Jogos e Brinquedos. Aprendizagem. Ensino. Educação Física e treinamento.

\section{PLAYING IN CHILDHOOD AND PHYSICAL EDUCATION TEACHER}

ABSTRACT: This aims to analyze the toy and games contribution, experienced in childhood, for initial training of physical education teachers. The survey was conducted with 27 students in the 5th period of Physical Education course at the Federal University of Paraíba, they responded to a structured questionnaire. Data were analyzed using the technique of content analysis. According to survey participants, the use of the

\footnotetext{
${ }^{1}$ Mestranda em Ciências das Religiões pela Universidade Federal da Paraíba (UFPB), Especialista em Fisiologia do Exercício pelas Faculdades Integradas de Patos (FIP), Graduada em Licenciatura Plena em Educação Física pela Universidade Federal da Paraíba (UFPB) e membro do Grupo de Estudos e Pesquisas em Corporeidade, Cultura e Educação (GEPEC), João Pessoa-PB, Brasil.

${ }^{2}$ Graduada em Licenciatura Plena em Educação Física pela Universidade Federal da Paraíba (UFPB), João Pessoa-PB, Brasil.

${ }^{3}$ Graduada em Licenciatura Plena em Educação Física pela Universidade Federal da Paraíba (UFPB), João Pessoa-PB, Brasil.

${ }^{4}$ Professor Associado da UFPB, Departamento de Educação Física, professor de Pós-graduação em Educação Física associado UPE/UFPB; líder do GEPEC - Grupo de Estudos e Pesquisas em Corporeidade, Cultura e Educação - CNPq/CCS/UFPB.

Licere, Belo Horizonte, v.17, n.1, mar/2014 
toy in their classes facilitates the process of teaching and learning, provides motor development, appropriate uses of popular games classes and assists in the teaching of value of coexistence. Therefore, we consider it important to rescue the culture of toys in the training of physical education teachers in view of the process of self-knowledge and experience.

Keywords: Play and Playthings. Teaching. Learning. Physical Education and Training.

\section{INTRODUÇÃO}

É na ação de brincar que a criança apropria-se da realidade, dando-lhe significado. As brincadeiras concedem à criança experiências afetivas, cognitivas e de interação social. Piaget (1975) relata a importância da brincadeira e sua ligação com a realidade e a fantasia, afirmando que quando a criança brinca, ela faz seu próprio mundo.

A brincadeira é um desafio que é reconhecido pela criança e que lhe dá prazer. Brincar é uma atividade que facilita a aprendizagem da criatividade, e de imaginação, bem como preparar-se para a vida adulta. Para desenvolver as brincadeiras são utilizados objetos, que dão um sentido lúdico a atividade.

Os brinquedos podem ter pelo menos duas definições, ou é aquilo que é usado como suporte durante a brincadeira ou é uma representação social que é dada a um objeto industrializado ou artesanal, podendo estes serem ou não usados numa situação de brincadeira, conservando seu caráter de brinquedo. Desta forma, os brinquedos são um meio por onde as crianças aprendem os significados da interação social.

\footnotetext{
Se o brinquedo é um objeto menor do ponto de vista das ciências sociais, é um objeto de profunda riqueza. A sua sombra, a sociedade se mostra duplamente naquilo que é mais, sobretudo naquilo que se dá a conhecer as suas crianças. Assim sendo, mostra a imagem que faz da infância. $O$ brinquedo é um dos reveladores de nossa cultura, incorpora nossos conhecimentos sobre a criança ou, ao menos, as representações largamente difundidas que circulam as imagens que nossa sociedade é capaz de segregar (BROUGÈRE, 2000, p. 98).
} 
A criança desde o seu nascimento está inserida num mundo de significados e representações que são construídos culturalmente. E é por meio da interação com outras crianças que elas passam por um processo de autopercepção e autoconhecimento no ambiente da brincadeira, reconstruindo seu significado (CARVALHO; PEDROSA, 2002).

Assim, as crianças ao observar as ações dos adultos tentam aprendê-las e reconstruí-las nos espaços de suas brincadeiras, inventando cenários, personagens e novas possibilidades do brincar, acontecendo o chamado faz-de-conta. Desta forma, os brinquedos são depósitos de valores sociais que podem determinar a maneira como as crianças veem o mundo. Para Brougère (1998) as concepções do brincar são construções que estão ligadas às representações da criança de cada época.

[...] a criança penetra num mundo extremamente diferente do mundo dos adultos, que é o mundo da fantasia, do faz-de-conta. Viajando pela fantasia, a criança vai longe. Conhece coisas que nós, adultos, já vivemos e esquecemos, e muitas vezes vai além de quase todos os adultos (FREIRE, 2005, p. 37).

Sendo assim, a brincadeira é uma verdadeira fonte de comunicação, pois até mesmo quando a criança brinca sozinha, por meio do faz de conta, ela imagina que está conversando com alguém ou com seus brinquedos (CORDAZZO; VIEIRA, 2007). É difícil encontrar uma criança que não goste de brincar, de dar formas à sua imaginação, por meio da fantasia. Segundo Masseti (1998), o brincar não tem tempo para acontecer, depende de se permitir a brincadeira.

Nas brincadeiras o brinquedo é necessário não só para divertimento da criança, mas também, para a educação. Mas, para que ele tenha caráter educativo, é preciso que se tenha a intervenção de um adulto.

Se a brincadeira é inata, cabe aos adultos que cuidam da criança iniciá-la em tal prática. Precisa haver um ambiente favorável, tempo, espaço e envolvimento daqueles que são responsáveis pela educação das crianças [...] O papel do adulto e das instituições escolares seria no sentido de dar um 
$\mathrm{Na}$ escola, o professor tem um papel fundamental no processo educativo da criança, ele deve orientar como escolher e utilizar o brinquedo. Desta forma, Tardif (2002) acredita que os professores devem possuir tanto os conhecimentos referentes à educação quanto utilizar-se de suas experiências cotidianas, sendo esta uma retomada crítica dos saberes adquiridos antes ou durante a prática profissional. Por exemplo, durante as aulas de Educação Física, os professores devem utilizar o brinquedo para levar os alunos a construir seus próprios roteiros, para que eles possam dar significados às brincadeiras num contexto do seu próprio mundo e possa conhecer as diferentes culturas nas quais esse brinquedo está inserido.

Essas considerações despertaram nosso interesse em analisar a contribuição do brinquedo e das brincadeiras vivenciadas na infância para formação inicial profissional dos professores de Educação Física. Tal estudo é relevante, pois permite investigar o significado da representação social do brinquedo e da brincadeira na infância e compreender de que modo a brincadeira pode interferir na formação dos professores de Educação Física e qual contribuição pedagógica dos brinquedos e brincadeiras vividas para os futuros professores.

\section{METODOLOGIA}

\section{Sujeitos da pesquisa}

Os sujeitos da pesquisa são 27 estudantes do $5^{\circ}$ período do curso de Licenciatura Plena em Educação Física da Universidade Federal da Paraíba (UFPB) no ano de 2008, sendo 13 do gênero feminino e 14 do gênero masculino, na faixa entre 20 e 34 anos de idade. A maioria dos estudantes já tinha experiências de ensino; muitos deles já 
estagiavam em alguma escola, academia de ginástica ou participavam de projetos de extensão promovidos pela Universidade.

Esses alunos foram escolhidos para compor a pesquisa, pois estavam matriculados na disciplina de Didática da Educação Física, cujo professor estava desenvolvendo a temática: “o professor de Educação Física e a brinquedoteca”, apontando-a por meio de discussão textual e oficina de brinquedos artesanais vividos na infância como mais uma possibilidade de intervenção do professor.

\section{Instrumento}

Foi utilizado para coleta de dados um questionário semi-estruturado contendo 9 (nove) questões subjetivas, que foi aplicado aos alunos em sala de aula, durante as aulas da disciplina de Didática da Educação Física. Neste contexto registramos o significado que cada brinquedo construído naquela oficina teve para si, em relação com a infância. Nesse questionário constam as falas de cada participante em relação à representação do brinquedo e da brincadeira na sua infância. Estas falas, ao longo do texto, foram representadas pelo nome do brinquedo e não o nome do autor da fala.

As questões são descritivas e têm por finalidade estimular os sujeitos da pesquisa a esboçar um quadro mais geral sobre os acontecimentos e ações ao utilizar o brinquedo e a brincadeira nas aulas de Educação Física e qual o sentido desses para os graduandos de Educação Física.

\section{Método de procedimento}

A coleta teve seu início nas aulas da disciplina Didática da Educação Física, o professor responsável pediu que os alunos construíssem em sala de aula brinquedos de materiais alternativos, de fácil construção, apontando como mais uma possibilidade de 
intervenção do professor na escola. Logo após construir os brinquedos, os alunos tinham que responder a um questionário falando sobre a importância dos brinquedos e brincadeiras na sua infância e qual a contribuição para o seu futuro exercício profissional. Essas aulas e a coleta dos dados aconteceram durante o mês de setembro de 2008, nas salas de aula do Departamento de Educação Física da Universidade Federal da Paraíba.

Foi assinado o Termo de Consentimento Livre e Esclarecido e encaminhado ao Conselho de Ética em Pesquisa, do Centro de Ciências da Saúde da Universidade Federal da Paraíba - UFPB; a pesquisa foi aprovada com protocolo n. 0193.

\section{Tratamento e análise das informações}

As informações foram analisadas a partir da técnica de Análise de Conteúdo, pois temos o objetivo de garantir a descoberta do verdadeiro significado dos aspectos e fenômenos da vida social dos indivíduos. Para Bardin (2002, p. 38) "a análise de conteúdo é um conjunto de técnicas de análise das comunicações que utilizam procedimentos sistemáticos e objetivos de descrição do conteúdo das mensagens”.

Seguimos a seguintes etapas para a análise de conteúdo: uma pré-análise, depois uma exploração do material e tratamento dos resultados e interpretação. O conteúdo manifesto das respostas, na tentativa de obter seus significados, foi catalogado em quatro unidades de registro, memória do prazer de brincar, aprender a conviver, motricidade e aprendizagem cultural.

\section{RESULTADOS E DISCUSSÃO}

Os brinquedos construídos pelos graduandos foram: pipa, cataputex, futebol de pregos, copBall, twister, dominó animado, dedoche, telefone, role e toque, tangran, boneco de meia, baralho animal, jogo de argolas, tampinharol, bolha de sabão, lança 
tampas, super fliper, pula Ball, resta 1, estica e puxa, jogo da memória, jogo de damas, mini tênis, sinuca de gude, estica e puxa, plast Ball e peteca.

No questionário aplicado, identificamos que dos 27 alunos participantes, 17 brincaram com seu brinquedo na infância e que a brincadeira envolvia outras pessoas como, amigos, irmãos e pais. Os outros 10 que não havia brincado, apenas fabricaram o brinquedo porque viram alguém brincar.

Também lhes foi perguntado se esses brinquedos contribuíram para sua formação pessoal e o que eles representam para a futura vida profissional. Apenas uma pessoa respondeu que o brinquedo não tinha nenhum significado especial. Os outros investigados responderam que o brinquedo contribuiu para seu crescimento e ajudam no desempenho profissional, como por exemplo, a utilização das experiências vivenciadas na aplicação de suas aulas.

Observamos ainda, que a memória dessas brincadeiras encontra-se bem nítida, a maioria dos alunos escreveu que o brinquedo confeccionado em sala de aula traz recordações de algum momento de sua infância. Lembranças de quando brincava com os amigos, de quando brincava na rua, das discussões com colegas, de como aprendeu a brincar, dos valores e do prazer que tinha em realizar as brincadeiras. "Os velhos brinquedos não estão esquecidos e a criação de brinquedos se renova a cada geração, incorporando novos materiais" (GOMES-DA-SILVA; MARQUES; VIEIRA, 2010, p. $66)$.

As respostas também evidenciaram a relação entre brinquedo e brincadeira vividas com as aulas de Educação Física ministradas. O professor afirma que ao utilizar o brinquedo em suas aulas, as crianças podem se socializar, criar laços de afetividade, desenvolver a criatividade e a motricidade e resgatar a cultura popular. 
Os resultados e discussão foram analisados em quatro etapas interdependentes: a primeira analisa a memória do prazer de brincar. Na segunda etapa, apresenta como o brincar é importante para aprender a conviver. Na terceira etapa examinamos a motricidade. Já na quarta etapa analisamos a aprendizagem cultural por meio dos brinquedos.

\section{Memória do prazer de brincar}

A brincadeira é uma fonte inesgotável de comunicação, seja ela realizada sozinha ou com outras pessoas, porque nela a criança dá asas à imaginação e cria seu mundo de representações. Desta forma, percebemos que o brinquedo não se resume apenas a representação de uma atividade social. Segundo Winnicott (1975) é no brincar, que o indivíduo pode ser criativo e utiliza sua personalidade integral: é por meio da criatividade que o indivíduo descobre seu eu (self).

\footnotetext{
O mini tênis me lembra quando brincava com minha irmã no muro da minha casa (Respondente 1).

Me lembra do tempo em que eu passava horas de rosto no sol soltando pipa (Respondente 2).

Me lembra que logo no início eu não sabia brincar e meus irmãos ficavam bagunçando comigo (Respondente 3 ).

Lembro do dia que no meio da brincadeira todos ficaram entrelaçados, foi muito legal (Respondente 4).
}

Percebemos que a memória da infância é de um tempo que continua muito próximo dos corações e mentes dos alunos da pesquisa. Em princípio, todos, apesar de adultos, em algum momento de suas vidas brincaram. "Reconhecer nosso passado é também um modo de diferenciar as crianças reais de nossas representações de infância [...] fazer brincar quando nos tornamos gente grande é uma forma de perpetuá-lo" (FORTUNA, 2004, p. 50). 
A lembrança das brincadeiras da infância possibilita uma construção da identidade individual e coletiva baseada na experiência vivenciada por cada um. Sabendo-se que as brincadeiras fazem parte da infância de todos. Conforme vimos nos participantes da pesquisa, o professor que brincou resgata o prazer de brincar, e utiliza as brincadeiras para incentivar e proporcionar aos alunos vivências prazerosas.

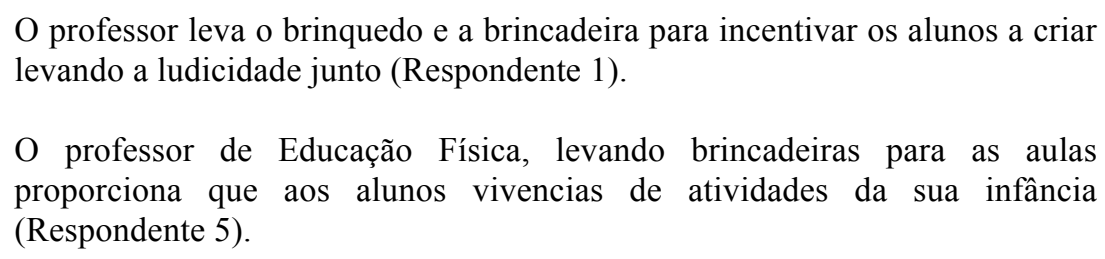

Porque por meio do resgate das brincadeiras da infância consigo realizar minhas aulas com mais ludicidade e prazer (Respondente 6).

Por meio da memória do prazer vivido, o professor tem mais facilidade em selecionar brincadeiras, que proporcionam aos alunos grande satisfação nos momentos das aulas. Bacha (2003) afirma que quando o professor oferece à criança conhecimentos ele pode permitir que ela construa junto sua história com uma linguagem própria, dando liberdade para que a criança seja dona de seus atos. "A experiência prova, assim um efeito de retomada crítica (retroalimentação) dos saberes adquiridos antes ou fora da prática profissional” (TARDIF, 2002, p.53).

Percebemos então que o professor de Educação Física pode utilizar-se de brincadeiras vividas para ensinar diferenciação cultural às crianças, promovendo e desenvolvendo os conceitos que elas podem adquirir brincando em casa ou na rua com os amigos e de maneira prazerosa. De acordo com Figueiredo e Rigo (2008), as brincadeiras, histórias e afetos da nossa infância têm grande significado cultural.

\section{Aprender a conviver}


Quando crianças, aprendemos a conviver com as pessoas que nos rodeiam. Aprendemos a dividir os brinquedos com o "coleguinha" e o espaço-tempo, a participar das mesmas brincadeiras, dos sorrisos, do choro. Segundo Freire (2007), “conviver é viver junto, no sentido, não só de estar perto, de estar ao lado de alguém, mas de compartilhar algo da vida, de realizar alguma coisa junto com alguém”.

\footnotetext{
Acho que a brincadeira me tornou uma pessoa feliz,alegre, espontânea. Uma pessoa que sabe perder e ganhar (Respondente 7).

Me fez aprender a conviver em grupo, socializar, desenvolver meus aspectos motores, afetivos e cognitivos (Respondente 3).

Na minha forma de expressão, de me relacionar e até na formação da minha personalidade (Respondente 8).

Ajudou no trabalho coletivo, em como tratar o colega. Ajudou-me a entender que ganhar nem sempre é possível (Respondente 5).
}

Percebemos que para os sujeitos da pesquisa, o brincar foi importante para a aprendizagem, reforçou a construção do conhecimento e ampliou as relações sociais, bem como pelo prazer que essas brincadeiras proporcionaram e a construção dos valores importantes para o convívio em sociedade. É brincando que o professor possibilita a criança inventar e construir, liberar seus desejos e dar sentido às experiências vivenciadas por eles, atribuindo relações e amizades que contribuirão para a sua formação como cidadão. Por isso, Pires (1989) afirma que a brincadeira e o jogo infantis preparam a criança para o convívio social.

Neste sentido, de acordo com as respostas dos analisados confirmamos a importância do brinquedo para o crescimento pessoal e social. Desta forma, o brinquedo auxilia o profissional de Educação Física a ensinar a construção de valores, e o aprender a conviver.

\section{Motricidade}


O desenvolvimento motor é um processo de mudanças comportamentais contínuas de fundamental importância no comportamento motor das crianças. Gallahue e Ozmun (2005) descrevem que as crianças precisam de um leque de oportunidades e instrução para realizar atividades motoras, tendo como objetivo evoluir na sua capacidade de movimentar-se. Com o aumento da diversidade e complexidade de movimentos, a criança desenvolve aprendizagens de novos movimentos a partir daqueles que já dominavam.

De acordo com as falas dos participantes da pesquisa as brincadeiras e os brinquedos contribuem para a organização, desenvolvimento e aprimoramento dos movimentos.

Os brinquedos e brincadeiras ajudam a promover e desenvolver aspectos motores (Respondente 9).

A brincadeira está diretamente ligada a infância, pois trabalha e exercita o desenvolvimento motor e intelectual na formação da criança (Respondente 2).

Para Gallahue e Ozmun (2005), é por meio das brincadeiras que as crianças tomam consciência de seu corpo e de suas capacidades motoras. "Brincar também serve como importante facilitador do crescimento cognitivo e afetivo da criança pequena" ( $p$. 236). Seguindo essa linha de raciocínio, Piaget (1975) afirma que o brinquedo tem uma função biológica e está ligada ao desenvolvimento cognitivo da criança cuja inteligência motora é a primeira a se manifestar no ser humano.

Segundo o relatos, os professores utilizam as brincadeiras vividas para estimular as capacidades motoras das crianças durante as aulas de Educação Física, fazem isso integrando os conhecimentos motores, para que eles possam fornecer um significado sobre o desenvolvimento motor em cada nova brincadeira. Utilizando-se dos brinquedos 
o professor ajuda as crianças a passarem por um processo contínuo de mudanças, organizando os movimentos dentro de uma relação espaço-temporal.

Segundo os graduandos:

O professor é quem vai facilitar o processo de ensino-aprendizagem e ajudar no desenvolvimento das habilidades motoras por meio das brincadeiras (Respondente 3).

O professor com o brinquedo vai proporcionar ao aluno o desenvolvimento motor, a coordenação, noções espaciais e temporais (Respondente 2).

Neste caso, ao professor é indicado utilizar a brincadeira como estratégia de ensino para criar situações "incluindo oportunidades para a prática, o encorajamento e a instrução são cruciais para o desenvolvimento de padrões de amadurecimento dos movimentos" (GALLAHUE; OZMUN, 2005, p.261) e para que os alunos possam conhecer e desfrutar de suas habilidades corporais. É preciso que haja a troca de experiências, objetivando o desenvolvimento das capacidades motoras das crianças.

Com isso o uso das brincadeiras da infância pelo professor de Educação Física tem papel importante no ambiente escolar, podendo dar condições adequadas às crianças, para que adquiram uma maior quantidade de experiências motoras. Assim, ao reviver brincadeiras o professor envolve os alunos no desempenho das suas aptidões motoras, permitindo que as crianças descubram a si mesmas.

\section{Aprendizagem cultural}

Os vestígios da existência de brinquedos e brincadeiras vivenciadas pelas diferentes culturas ao longo dos tempos são antigos. Vasconcelos (2006) revela que na região do Brasil, nas grutas da Serra da Capivara - São Raimundo Nonato, Piauí, existem figuras gravadas de 6 mil anos que representam brinquedos e brincadeiras que, possivelmente, foram vivenciadas por crianças. Desta forma, percebemos que o ato de 
brincar acompanha a evolução da humanidade. Para Antério e Gomes-da-Silva (2012, p. 925) “o brinquedo, em sua trajetória histórica, traz um rol de sentidos e significados para cada época, porque ele é parte indissociável do brincar da criança em cada cultura e período".

Os brinquedos e as brincadeiras fazem parte da cultura infantil, sendo transmitida de geração para geração. Porém, atualmente as brincadeiras populares estão sendo substituídas por brinquedos tecnológicos: vídeo games, computadores, televisão. O reviver das brincadeiras "esquecidas" se faz necessário para que a criança tenha acesso ao saber popular, sendo este um acervo.

De acordo com as falas dos graduandos, utilizar o brinquedo artesanal nas aulas de Educação Física favorece ao resgate da cultura infantil, ao proporcionar vivências antigas e prazerosas, que estimulam a criança a entender sobre a cultura de seu povo.

As aulas podem Resgatar a cultura e mostrar que pode sim haver uma relação entre a Educação Física e os brinquedos e brincadeiras, abrindo um leque de oportunidades (Respondente 7).

Nas aulas que uso o brinquedo proporciono que os alunos vivenciem atividades e ocorra um resgate dos brinquedos da infância (Respondente 5).

A Educação Física favorece a criança resgatar ou descobrir o prazer da infância por meio das brincadeiras (Respondente 10).

Sendo assim, é de fundamental importância que os professores mantenham as crianças em contato com uma tradição cultural que lhes é herdada. Pois, segundo Gomes-da-Silva; Caminha (2007, p. 75) “entendemos serem as brincadeiras que, de modo despercebido, atualizam a cultura humana, registram a existência de um fundo cultural". Desta forma, os futuros professores percebem a importância de se desenvolver uma prática pedagógica mais consistente que tenha relação integral com a vida dos alunos. 


\section{CONCLUSÃO}

Desenvolvemos aqui, elementos que apresentam como o brinquedo tem importância na vida de estudantes de Educação Física, porque o brincar foi e continua sendo importante para o desenvolvimento infantil, para a aprendizagem, para a formação de conceitos e valores, ou seja, para a produção do conhecimento.

Vimos que a brincadeira esteve presente na vida dos futuros professores de Educação Física e, por meio da criação do brinquedo em sala de aula, se permitiram relembrar como o brinquedo teve interferência no seu crescimento pessoal e social. Estes graduandos são adultos que não esqueceram a riqueza do brincar, dando novos significados e representações ao brinquedo. São adultos, que entenderam o brincar como uma grande experiência de construção e reconstrução da realidade externa e interna.

Nestes termos, o professor de Educação Física se coloca como um facilitador, abrindo espaço para que as transformações aconteçam livremente. Segundo Bacha (2003) o professor deve permitir que a criança tome consciência de sua história, para recriá-la de maneira lúdica e prazerosa.

Desta forma, consideramos importante o reviver dos brinquedos para a formação dos professores, visto que estes, ao terem brincado entram num processo de autoformação ao relembrar os saberes iniciais em confronto com a sua prática docente. “Assim seus saberes vão-se constituindo a partir de uma reflexão na e sobre a prática" (NUNES, 2001, p. 30), desenvolvendo um saber prático baseado em suas experiências cotidianas com os alunos.

Esse trabalho contribui para revelar a importância das experiências vividas do brincar na infância, quando revividas como saberes docentes, a partir do momento em que o professor passe a unir suas experiências lúdicas aos conteúdos de suas aulas. 


\section{REFERÊNCIAS}

ANTÉRIO, D.; GOMES-DA-SILVA, P. N. Relação sociocultural dos brinquedos artesanais vendidos em feiras livre. Educ. Real., Porto Alegre, v. 37, n. 03, p. 923-941, set/dez, 2012.

ARAÚJO, V. C. Reflexões sobre o brincar infantil. Revista Educação em destaque. Colégio Militar de Juiz de Fora, v. 01, p. 04-13, 2008.

BACHA, M. N. Psicanálise e Educação: laços refeitos. São Paulo: casa do psicólogo, 2003.

BARDIN, L. Análise de conteúdo. Lisboa: Edições 70, 2002.

BROUGÈRE, Gilles. Jogo e educação. Porto Alegre: Artes Médicas, 1998.

Brinquedo e cultura. 3. ed. São Paulo: Cortez, 2000.

CARVAlHO, A. M. A.; PEDROSA, M. I. Cultura no grupo de brinquedo. Revista Estudos de Psicologia, v. 10, n. 1, p. 181-188, 2002.

CORDAZZO, S. T. D.; VIEIRA, M. L. A brincadeira e suas implicações nos processos de aprendizagem e de desenvolvimento. Estudos e Pesquisa em Psicologia, UERJ, v. 07, n. 01, p. 92-104, abril 2007.

FORTUNA, T. R. Vida e morte do brincar. In: ÁVILA, I. S. (Org.). Escola e sala de aula: mitos e ritos. Porto Alegre: editora da UFRGS, 2004.

FREIRE, J. B. Educação de corpo inteiro: teoria e prática da educação física. São Paulo: Scipione, 2005.

Conviver e aprender. In: GOMES-DA-SILVA, P. N.; CAMINHA, I. O. (Org.). Aprender a conviver: um enigma para a educação. João Pessoa: Ed. UniversitáriaUFPB, p. 49-64, 2007.

FIGUEIREDO, M. X. B; RIGO, L. C. memorias das infancias no proceso de formação das educadoras. Pensar a prática, v.03, n.11, p. 261-268, set/dez, 2008.

Gallahue, D. L, OZMUN, J. C. Compreendendo o desenvolvimento motor: bebês, crianças, adolescentes e adultos. São Paulo: Phorte, 2005.

GOMES-DA-SILVA, P. N.; CAMINHA, I. O. (Org.). Aprender a conviver: um enigma para a educação. João Pessoa: Ed. Universitária - UFPB, 2007.

. GOMES-DA-SILVA, P. N.; MARQUES, A. C. O.; VIEIRA, T. I. Oficinas de brinquedos e brincadeiras. João Pessoa: Ed. Universitária - UFPB, 2010.

MASETTI, M. Soluções de palhaço. São Paulo: Palas Athena, 1998. 
NUNES, C. M. F. saberes docentes e formação de profesores: um breve panorama da pesquisa brasileira. Rev. Educação e Sociedade, v. 74, n. 74, p. 27-42, Abril, 2001.

PIAGET, J. A formação do símbolo na criança: imitação, jogos, sonho, imagem e representação. Rio de Janeiro: Zahar, 1975.

PIRES, G. N. L. A brincadeira e o jogo infantil como representação do mundo adulto e aprendizagem dos modelos sociais. Educação em debate. v.17, n.18. p. 67-77, 1989.

TARDIF, M. Saberes docentes e formação profissional. Petrópolis: Vozes, 2002.

VASCONCELOS, M. S. Ousar brincar. In: ARANTES, V. A. (Org.). Humor e alegria na educação. São Paulo: Summus, p.57-74, 2006.

WINNICOTT, D. W. O brincar e a realidade. Rio de Janeiro: Imago, 1975.

\section{Endereço dos Autores:}

Alana Simões Bezerra

Rua Pedro Barbosa Filho, 246A. Castelo Branco III.

CEP: 58050-610 - João Pessoa - PB

Endereço Eletrônico: alana_simoes_edf@hotmail.com 